\title{
Antibiotic-resistant Staphylococcus aureus in dermatology and burn wards
}

\author{
G. A. J. AYLIFFE, WENDA GREEN, R. LIVINGSTON, AND E. J. L. LOWBURY \\ From the Hospital Infection Research Laboratory and Bacteriology Department, Dudley Road Hospital and \\ MRC Industrial Injuries and Burns Unit, Birmingham
}

SUMMARY Staphylococcus aureus isolated between 1967 and 1975 from the nose and skin lesions of patients in dermatology wards and from the burns of patients in a burns unit in Birmingham showed a high incidence of multiple antibiotic-resistant strains in both environments. Over $20 \%$ of tho strains isolated from patients on admission to the dermatology wards were multiresistant. Resistance to benzylpenicillin, tetracycline, erythromycin, and fusidic acid was common in the dermatolog $\vec{z}$ wards; a smaller proportion of strains were resistant to lincomycin, and few (since 1972 none) were resistant to methicillin; resistance to novobiocin and chloramphenicol was uncommon. In the burn unit, fusidic acid resistance was uncommon, but resistance to benzylpenicillin, tetracycline, ery thromycin, novobiocin, neomycin, methicillin, and lincomycin was common. Several of the antibiotics to which resistance was common in the burns unit were rarely if ever used there; strains resistant to these antibiotics probably remained common in the ward through the frequent use of other antibiotics, especially erythromycin, to which these strains were also resistant.

Although infections caused by antibiotic-resistant strains of Staphylococcus aureus are less of a clinical problem than formerly, such organisms are still frequently isolated from septic operation wounds, skin lesions, and burns. Some strains show resistance to most of the useful non-toxic antibiotics available (Ayliffe, 1973). These highly resistant strains are often found in dermatological and burn wards, where cross-infection is common and where many patients are treated with topical and systemic antibiotics at some time during their long periods of illness. Resistance to neomycin and fusidic acid has followed the topical use of these antibiotics (Lowbury et al., 1962, 1964; Alder and Gillespie, 1967; Smith et al., 1975).

In the present study, the results of surveys of staphylococcal carriage in dermatological wards in a Birmingham hospital and an investigation into the possible origin of resistant strains in these wards are reported; data are also presented on staphylococci isolated from burns in the Birmingham Accident Hospital during the same period of time.

\section{Methods}

In each survey at the Birmingham Skin Hospital nose swabs and swabs from lesions were taken from

Received for publication 27 May 1976 all patients in three wards, and nose swabs were taken from staff on duty. One survey was made in 1967 and several surveys a year were made betwee? 1970 and 1975. In February and March 1974, nose and skin swabs were taken from 115 patients of admission and on discharge from the dermatologicat wards.

In the Burns Unit of the Birmingham Acciden Hospital swabs moistened with peptone water were used for sampling the burns of patients at change of dressings and at operation, or daily in those treate $\bar{\Phi}$ by the exposure method. In addition, a series of 100 isolates of Staph. aureus was obtained from the nares of patients attending the casualty departmen as examples of staphylococci in the community.

BACTERIOLOGY METHODS

In the dermatology wards Nose swabs wer\& cultured on nutrient agar containing phenolphthaleig diphosphate (Barber and Kuper, 1951) and $1 \%$ serum; other swabs were cultured on blood agaf and McConkey medium. All plates were incubateep for 18 hours, and presumptive Staph. aureus (phosphatase positive) was confirmed by slide or tub $\vec{\theta}$ coagulase tests. Strains of Staph. aureus isolate from the surveys were tested for sensitivity to antibiotics by the ditch-plate method. The ditches contained benzylpenicillin, $10 \mathrm{units} / \mathrm{ml}$; novobiocin 
Table 1 Antibiotic resistance of Staph. aureus isolated from patients' noses in surveys of dermatological wards, 1967-74

\begin{tabular}{|c|c|c|c|c|c|c|c|}
\hline \multirow[t]{2}{*}{ Antibiotic } & \multicolumn{7}{|c|}{ Percentage of patients carrying resistant strains } \\
\hline & 1967 & 1970 & 1971 & 1972 & 1973 & 1974 & 1975 \\
\hline $\begin{array}{l}\text { Benzylpenicillin } \\
\text { Tetracycline } \\
\text { Erythromycin } \\
\text { Novobiocin } \\
\text { Chloramphenicol } \\
\text { Neomycin/kanamycin } \\
\text { Methicillin/cloxacillin } \\
\text { Fusidic acid } \\
\text { Lincomycin/(clindamycin) }\end{array}$ & $\begin{array}{l}20 \\
35 \\
17 \cdot 5 \\
5 \\
0 \\
10 \\
-2 \cdot 5 \\
-\end{array}$ & $\begin{array}{l}37 \cdot 8 \\
29 \cdot 2 \\
10 \cdot 9 \\
6 \\
3 \cdot 6 \\
11 \\
1 \cdot 2 \\
8 \cdot 5 \\
0\end{array}$ & $\begin{array}{l}49 \\
42 \cdot 2 \\
26 \cdot 5 \\
3 \cdot 9 \\
1 \\
13 \cdot 7 \\
2 \cdot 9 \\
21 \cdot 6 \\
15 \cdot 7\end{array}$ & $\begin{array}{l}41 \cdot 4 \\
16 \\
10 \cdot 9 \\
1 \cdot 2 \\
0 \\
4 \cdot 2 \\
0 \\
8 \\
4 \cdot 6\end{array}$ & $\begin{array}{c}42 \cdot 1 \\
27 \cdot 7 \\
22 \cdot 6 \\
1 \cdot 8 \\
0 \\
10 \\
0 \\
13 \cdot 8 \\
7 \cdot 5\end{array}$ & $\begin{array}{l}40 \cdot 8 \\
32 \cdot 7 \\
22 \\
0 \\
1 \cdot 1 \\
23 \cdot 9 \\
0 \\
12 \cdot 1 \\
4\end{array}$ & $\begin{array}{c}47 \cdot 3 \\
35 \cdot 3 \\
32 \cdot 7 \\
0 \cdot 7 \\
0 \cdot 7 \\
28 \\
0 \\
20 \\
6 \cdot 7\end{array}$ \\
\hline Number of patients & 40 & 82 & 102 & 237 & 159 & 272 & 150 \\
\hline
\end{tabular}

- not tested

lincomycin, fusidic acid, erythromycin, and methicillin, $10 \mu \mathrm{g} / \mathrm{ml}$; streptomycin, tetracycline, chloramphenicol, and neomycin or kanamycin, $50 \mu \mathrm{g} / \mathrm{ml}$. Plates for methicillin-resistance tests were incubated at $30^{\circ} \mathrm{C}$. Staph. aureus isolated from the noses or lesions of patients on admission and discharge were tested by the disc method (Oxoid multi-disc) for sensitivity to the same antibiotics apart from novobiocin and chloramphenicol. The minimum inhibitory concentration (MIC) of fusidic acid (Fucidin) and lincomycin for some strains was determined by a tube dilution method. All strains from surveys were phage typed with the routine set of phages kindly supplied by the Central Public Health Laboratory, Colindale.

In the Burns Unit Swabs were cultured on blood agar containing $4 \%$ New Zealand agar and in cooked meat broth, which was subcultured after 48 hours' incubation to blood agar. Presumptive Staph. aureus colonies were picked and confirmed by a tube coagulase test.

The sensitivity of Staph. aureus to antibiotics was tested by a ditch plate method similar to that described above, but with $25 \mu \mathrm{g} / \mathrm{ml}$ methicillin and $10 \mu \mathrm{g} / \mathrm{ml}$ neomycin in the agar of the ditch for tests of sensitivity to these antibiotics. In 1972, methicillin sensitivity tests were carried out on ditch plates incubated at both $30^{\circ} \mathrm{C}$ and $37^{\circ} \mathrm{C}$. The same strains were found to be fully sensitive (S) by both methods, but a much larger proportion of strains were described as fully resistant (R) or moderately resistant ('R') in tests at $30^{\circ} \mathrm{C}$ than in those done at $37^{\circ} \mathrm{C}$, and a much larger proportion were described as moderately sensitive (' $S$ ') in the test done at $37^{\circ} \mathrm{C}$. Methicillin resistance in $1972,1973,1974$, and 1975 includes results shown as $R$ and ' $R$ ' at $30^{\circ} \mathrm{C}$ (corresponding, in parallel tube dilution tests at $30^{\circ} \mathrm{C}$, to MICs of 32 to $128 \mu \mathrm{g} / \mathrm{ml}$ and 16 to $32 \mu \mathrm{g} / \mathrm{ml}$ respectively). In the earlier period, methicillin resistance is shown as $R+{ }^{\prime} R$ ' + ' $S$ ' at $37^{\circ} \mathrm{C}$ (corresponding to MICs of 8 to $128 \mu \mathrm{g} / \mathrm{ml}$ at $30^{\circ} \mathrm{C}$ ). In the year 1972 , parallel tests made at $30^{\circ} \mathrm{C}$ and at $37^{\circ} \mathrm{C}$ showed a close similarity of results when resistance was expressed in these terms.

\section{Results}

\section{DERMATOLOGY WARDS}

The antibiotic resistance of strains of Staph. aureus isolated from the noses of patients in the surveys is shown in Table 1. Carriage of strains resistant to penicillin, tetracycline, and, to a lesser extent, erythromycin and neomycin (kanamycin) occurred throughout the period investigated. Strains resistant to methicillin and chloramphenicol were isolated on a few occasions only. Strains resistant to fusidic acid were first isolated in 1967 and to lincomycin in 1971. Strains resistant to both these antibiotics have remained in the wards, and strains of similar resistance were isolated from the skin lesions of many of the patients and from the noses of staff. The MICs for strains resistant to fusidic acid were 8 to $16 \mu \mathrm{g} / \mathrm{ml}$ and for lincomycin-resistant strains $>128 \mu \mathrm{g} / \mathrm{ml}$. In most instances the frequency of isolation of resistant strains was lower in 1972 than in previous years. This was apparently due to the closing of the wards for several weeks after a small outbreak of eczema vaccinatum in a few patients. Since 1972 the incidence of resistant strains, particularly to fusidic acid and neomycin, has increased.

Antibiotic sensitivity patterns and phage patterns In 1967 , the more resistant strains were usually of phage group III patterns, eg, 6/47/53/54/75/77/83A (Ayliffe, 1970). From 1970 to 1974 a wide range of antibiotic resistance patterns and phage types was obtained. These were mainly phage group III patterns, often the same as in 1967. A selection of these strains is shown in Table 2. There appeared to be no correlation between antibiotic resistance patterns and phage types. 
Table 2 Antibiotic resistance and phage patterns in strains of Staph. aureus

\begin{tabular}{ll}
\hline Antibiotic resistance pattern $^{1}$ & Phage pattern \\
\hline P T E N L F & $\mathbf{8 4 / 7 7}$ \\
P T E N & $6 / 47 / 53 / 54 / 77$ \\
P T E N & $84 / 85$ \\
P T E F & $\mathbf{8 4 / 7 7 / 8 3 A}$ \\
P T E F L & $84 / 54 / 77$ \\
T E F No K & $\mathbf{8 0}$ \\
\hline
\end{tabular}

${ }^{1} \mathrm{P}=$ penicillin $; \mathrm{T}=$ tetracycline $; \mathrm{E}=$ erythromycin $; \mathrm{N}=$ neomycin $:$ $\mathbf{L}=$ lincomycin $;$ No $=$ novobiocin $;$ and $\mathbf{F}=$ fusidic acid

Table 3 Carriage of multiple-resistant strains of Staph. aureus before and after admission to hospital (nose or skin)

\begin{tabular}{llll}
\hline $\begin{array}{l}\text { Number of } \\
\text { patients }\end{array}$ & $\begin{array}{l}\text { Multiresistant } \\
\text { Staph. aureus } \\
\text { present on } \\
\text { admission }\end{array}$ & $\begin{array}{l}\text { Number of } \\
\text { patients } \\
\text { acquiring multi- } \\
\text { resistant } \\
\text { Staph. aureus }\end{array}$ & $\begin{array}{l}\text { Number of } \\
\text { patients losing } \\
\text { multiresistant } \\
\text { Staph. aureus }\end{array}$ \\
\hline 115 & 25 & 38 & 9 \\
\hline
\end{tabular}

Table 3 shows that over $20 \%$ of patients carried multiple-resistant strains (ie, resistant to two or more antibiotics) on admission to hospital. These were similar in sensitivity pattern to those present in other patients when discharged (eg, five patients, on admission, carried strains resistant to $P, T, E, F$, and $\mathrm{N}$, and two carried strains which were also resistant to lincomycin). Most of these patients had attended the outpatients department, and there was no evidence from case notes that any had been treated with fusidic acid. Seven of the patients had been treated with topical chlortetracycline and three with erythromycin at some time during the past few years. One of the patients with atopic eczema and carrying a strain resistant to $P, T, E, L$, and $N$ had been treated with chlortetracycline, tetracycline (two courses), lincomycin (three courses), topical neomycin and gentamicin, cephalexin, and cloxacillin during a 10-year period. No information was available on the treatment given to most of the patients by general practitioners.

BURNS WARDS

Table 4 shows the proportion of strains of Stapt高 aureus isolated from burns in the Birminghan Burns Unit in the same years as those represented if the study on dermatology wards. The data are not strictly comparable with those in Table 1 becaus Staph. aureus was isolated from a larger proportionof burns in the Burns Unit than from noses ot patients in the dermatology wards, and also because the data presented in Table 4 show repeated isola? tions from many burns. The incidence of resistances to penicillin, tetracycline, erythromycin, and neo-mycin/kanamycin was high in all years, althougit neomycin resistance declined a little after the withdrawal of that antibiotic in 1972 (Lowbury et al., 1972). In contrast with the findings in the dermatology wards, resistance to fusidic acid was low, but resistance to methicillin was high. There was a rising incidence of novobiocin and lincomycin resistance. Most of the staphylococci showed pattern\$ of multiple-resistance.

The number of strains resistant to an antibiotid in the ward is not necessarily proportional to the amount of the antibiotic used, for frequent use of ons antibiotic may exert a selection pressure favouring strains resistant to that antibiotic and to others thag are not in use or rarely used. Erythromycin has been used more than other antibiotics in the Burns Unif since 1974; for example, in the three months from September to November 1975, the numbers of patients treated with antibiotics were as follows erythromycin 90 , flucloxacillin 6 , ampicillin $2 \%$ amoxycillin 1 , fusidic acid 2 , gentamicin 2 , and co-trimoxazole 1 ; no patients received cephalosporins, lincomycin (or clindamycin), neomycin? (or kanamycin), novobiocin, or tetracyclines. These patterns have not changed much since 1974 wherf

Table 4 Antibiotic resistance of Staph. aureus isolated from burns

\begin{tabular}{|c|c|c|c|c|c|c|c|}
\hline \multirow[t]{2}{*}{ Antibiotic } & \multicolumn{7}{|c|}{ Percentage of strains resistant } \\
\hline & 1967 & 1970 & 1971 & 1972 & 1973 & 1974 & 1975 \\
\hline $\begin{array}{l}\text { Penicillin } \\
\text { Tetracycline } \\
\text { Erythromycin } \\
\text { Novobiocin } \\
\text { Chloramphenicol } \\
\text { Neomycin/kanamycin }\end{array}$ & $\begin{array}{c}91 \cdot 7 \\
52 \cdot 2 \\
70 \cdot 1 \\
0.02 \\
0.02 \\
64.0\end{array}$ & $\begin{array}{r}87 \cdot 7 \\
47 \cdot 9 \\
80 \cdot 2 \\
7 \cdot 9 \\
-\quad 79 \cdot 4\end{array}$ & $\begin{array}{r}81 \cdot 6 \\
82 \cdot 1 \\
91 \cdot 6 \\
19 \cdot 5 \\
-\quad 90 \cdot 2\end{array}$ & $\begin{array}{r}87 \cdot 7 \\
75 \cdot 9 \\
78 \cdot 1 \\
66 \cdot 0 \\
-\quad 69.6\end{array}$ & $\begin{array}{r}88 \cdot 5 \\
69 \cdot 1 \\
75 \cdot 0 \\
23 \cdot 8 \\
-\quad 36 \cdot 4\end{array}$ & $\begin{array}{r}88 \cdot 4 \\
72 \cdot 3 \\
77 \cdot 9 \\
42 \cdot 9 \\
-\quad \\
29 \cdot 6\end{array}$ & $\begin{array}{r}95 \cdot 5 \\
79 \cdot 1 \\
80 \cdot 7 \\
62 \cdot 7 \\
-\quad 61 \cdot 1\end{array}$ \\
\hline Methicillin & $39 \cdot 8^{1}$ & $44 \cdot 7^{1}$ & $24 \cdot 4^{1}$ & $\left.\begin{array}{l}59 \cdot 7^{1} \\
57 \cdot 1^{2}\end{array}\right\}$ & $22 \cdot 4$ & $40 \cdot 1$ & $55 \cdot 6$ \\
\hline $\begin{array}{l}\text { Fusidic acid } \\
\text { Lincomycin }\end{array}$ & $\begin{array}{l}0 \\
0\end{array}$ & $\begin{array}{l}0 \cdot 28 \\
20 \cdot 4\end{array}$ & $\begin{array}{l}0 \cdot 34 \\
73 \cdot 9\end{array}$ & $\begin{array}{r}1 \cdot 7 \\
65 \cdot 9\end{array}$ & $\begin{array}{r}2 \cdot 1 \\
24 \cdot 7\end{array}$ & $\begin{array}{r}1 \cdot 3 \\
43 \cdot 3\end{array}$ & $\begin{array}{r}2 \cdot 1 \\
66 \cdot 3\end{array}$ \\
\hline Number of strains tested & 6415 & 6000 & 9325 & 4961 & 6988 & 4265 & 5546 \\
\hline
\end{tabular}


erythromycin replaced cloxacillin as the antibiotic used for prophylaxis against Clostridium tetani in the non-immune and against Streptococcus pyogenes in the Burns Unit. It seems probable that erythromycin (and previously flucloxacillin or cloxacillin) exerted a selection pressure maintaining a high incidence of resistance to kanamycin and methicillin and to their analogues and also to novobiocin and lincomycin when these were associated (as they usually were) with erythromycin or methicillin resistance.

The numbers of Staph. aureus in 100 consecutive isolates from the noses of members of the general community that were resistant to these antibiotics in 1973 were as follows: penicillin 42, tetracycline 5, erythomycin 4, methicillin 1, kanamycin 1; no strain was resistant to novobiocin, fusidic acid or lincomycin. Apart from strains resistant to penicillin, the incidence of resistance to antibiotics was low or inapparent.

\section{Discussion}

Staphylococcal cross-infection occurs commonly in dermatological wards (Selwyn, 1965; Wilson et al., 1971), but the clinical effects are usually mild. Topical antibiotics, especially neomycin, are widely used and are often prescribed routinely with a steroid (Smith et al., 1975). Although attempts have been made to restrict the use of neomycin and fusidic acid, resistant strains have remained common. The group A haemolytic streptococcus, which is relatively resistant to these antibiotics, is also commonly isolated when they are used topically. Because $20 \%$ of patients admitted to hospital were found to carry multiple-resistant Staph. aureus, eradication has proved to be difficult. When the hospital was closed for several weeks in 1972, $10 / 77(13 \%)$ of the staff were carrying strains resistant to fusidic acid. These were treated with a gentamicin/chlorhexidine ointment (a method rarely used today because of the recognized hazard of gentamicin resistance), and the wards were cleaned before being opened. Despite a restriction in the use of topical fusidic acid, the number of patients carrying fusidic acid resistant strains in the nose or on the skin increased from $3 / 60(5 \%)$ to $15 / 113$ $(13 \%)$ in two months. This was apparently due to cross-infection after readmission of a carrier. More evidence is required to determine whether these multiple-resistant strains emerge during treatment at home, or whether cross-infection in outpatients is the main route. Cross-infection seems to be the more likely, as these strains are rarely isolated in the general population, but, if this is true, cross-infection must have occurred very quickly in some patients.
Most of the patients had not previously been inpatients.

The wide range of antibiotic resistance patterns with similar phage patterns suggests that transfer of plasmids may also occur (Ayliffe, 1970; Lacey, 1975). These highly resistant strains frequently colonize the nose and skin of patients without causing any obvious clinical lesions. However, such a patient may be a heavy disperser and responsible for widespread cross-infection in a surgical or maternity ward. Patients with skin disease admitted to acute surgical wards should be screened for carriage and isolated in a single room until bacteriologically clear. It must be stressed that this is to protect other patients, and that the risk to family, friends, or hospital staff is negligible. It seems likely that many of the strains resistant to neomycin, lincomycin, or fusidic acid found in general hospitals were originally acquired from the skin lesions of patients in dermatology wards. An outbreak of gentamicin (and tobramycin)-resistant Staph. aureus involving three hospitals has been reported recently (Speller et al., 1976) and about half of the infected patients were treated with systemic tobramycin or gentamicin. Another smaller outbreak of gentamicin-resistant staphylococcal infection has occurred in Birmingham (Bint, personal communication). The use of topical gentamicin is particularly likely to cause an increased incidence of gentamicin-resistant strains within the next few years. Of some interest was the small number of strains of staphylococci resistant to methicillin (or cloxacillin) and chloramphenicol. This is presumably due to the infrequent use of these antibiotics in dermatology wards; however, in surveys of general hospitals in the Birmingham Region, the incidence of methicillin-resistant strains has dropped from $2.4 \%$ in 1970 to $0.4 \%$ in $1973-74$, although the use of these antibiotics has remained unchanged.

Like skin lesions, burns are very prone to colonization with Staph. aureus, which usually causes no obvious pathological effects, although in severely burned patients it may cause invasive infection. The pattern of resistance of burn staphylococci was similar, in some respects, to that of staphylococci from skin lesions and from the nares of patients in the dermatology wards; there was a high incidence of multiple resistance and a very large proportion of the strains were resistant to penicillin, tetracyline, and erythromycin, the last reflecting a long-standing use of erythromycin in the treatment of streptococcal infection and more recent use in prophylaxis against Strep. pyogenes and also against tetanus in non-immune patients. The low incidence of fusidic acid resistance and the high incidence of methicillin/ 
cloxacillin resistance reflect the rare use of the former and the frequent use (until 1974) of the latter; the persistence of a high level of methicillin/ cloxacillin resistance in spite of the great reduction in use of these antibiotics in the Unit in 1974 is probably due to selection pressure by erythromycin therapy favouring strains with linked resistance to erythromycin and methicillin. Similar associated resistance to erythromycin and to methicillin may be the cause of the emergence and persistence of a high proportion of novobiocin-resistant and lincomycin-resistant strains, in spite of the fact that these antibiotics were not being used, and the persistence of a rather high incidence of neomycinresistance after withdrawal of neomycin and kanamycin in 1972.

Eradication of resistant strains from dermatology units is difficult for reasons already mentioned, but a complete restriction on the use of certain antibiotics, for example, fusidic acid and gentamicin, may eventually be effective. In general hospital wards, cross-infection can be more effectively controlled than in dermatology wards, but patients with skin diseases can be kept in special units where the clinical results of cross-infection are less hazardous.

In burns units, cross-infection ensures a continuing high incidence of multiresistant staphylococci, but as operation wounds are more likely to develop sepsis as the result of such colonization than are burn wounds, it is desirable that patients with burns should be treated in special units; if they are treated in general surgical wards, they should be nursed in separate rooms under source isolation to prevent the transfer of their bacteria to other patients in the ward (Lowbury et al., 1975).

We wish to thank the clinicians, nursing staff, and general practitioners for their cooperation. We also wish to thank Mrs J. Varney, SRN (Infection Control/Research Sister), Mr H. A. Lilly, FIMLS, and Mrs A. Kidson, FIMLS, of the MedicalResearch Council Industrial Injuries and Burn⿸\zh14 Research Unit at the Birmingham Accident Hospita ${ }_{-}$

References

Alder, V. G., and Gillespie, W. A. (1967). Influence o neomycin sprays on the spread of resistant staphylococc? Lancet, 2, 1062-1063.

Ayliffe, G. A. J. (1970). Stability of neomycin resistance in. Staphylococcus aureus. Journal of Clinical Pathology, 23? 19-23.

Ayliffe, G. A. J. (1973). Use of antibiotics and resistancêt In Current Antibiotic Therapy, edited by A. M. Geddes and J. D. Williams, pp. 53-63. Churchill Livingstone Edinburgh and London.

Barber, M., and Kuper, S. W. A. (1951). Identification oథ Staphylococcus pyogenes by the phosphatase reaction. Journal of Pathology and Bacteriology, 63, 65.

Lacey, R. W. (1975). Antibiotic resistance plasmids of Staphylococcus aureus and their clinical importance? Bacteriological Reviews, 39, 1-32.

Lowbury, E. J. L., Ayliffe, G. A. J., Geddes, A. M., anf Williams, J. D. (editors) (1975). Control of Hospita\# Infection: A Practical Handbook. Chapman and Hal|̄ London.

Lowbury, E. J. L., Babb, J. R., Brown, V. I., and Collins, B. J. (1964). Neomycin-resistant Staphylococcus aureus in a burns unit. Journal of Hygiene (Cambridge), 62, 221-228.

Lowbury, E. J. L., Babb, J. R., and Roe, E. (1972). Clearanc巳 from a hospital of Gram-negative bacilli that transfer carbenicillin-resistance to Pseudomonas aeruginosa. Lance 2, 941-945.

Lowbury, E. J. L., Cason, J. S., Jackson, D. M., and Millex R. W. S. (1962). Fucidin for staphylococcal infection of burns. Lancet, 2, 478-480.

Selwyn, S. (1965). The mechanism and prevention of cross? infection in dermatological wards. Journal of Hygiens (Cambridge), 63, 59-71.

Smith, R. J., Alder, V. G., and Warin, R. P. (1975). Pyogenic cocci in infantile eczema throughout one year. Britisक Medical Journal, 3, 199-201.

Speller, D. C. E., Stephens, M., Raghunath D., Viant, A. C유 Reeves, D. S., Broughall, J. M., Wilkinson, P. J., and Holt, H. A. (1976). Epidemic infection by a gentamicing resistant Staphylococcus aureus in three hospitals. Lancet 1, 461-466.

Wilson, P. E., White, P. M., and Noble, W. C. (1971) Infections in a hospital for patients with diseases of the skin. Journal of Hygiene (Cambridge), 69, 125-132. 